\title{
In-situ analysis of fiber structure development for isotactic polypropylene
}

Young-Ah Kang ${ }^{1,2}$, Kyoung-Hou Kim ${ }^{3}$, Soichiro Ikehata ${ }^{1}$, Yutaka

Ohkoshi $^{1, *}$, Yasuo Gotoh ${ }^{1}$, Masanobu Nagura ${ }^{1}$, and Hiroshi Urakawa ${ }^{4}$

${ }^{1}$ Faculty of Textile Science and Technology, Shinshu University, 3-15-1 Tokida, Ueda, Nagano 386-8567, Japan

${ }^{2}$ Research Institute of Human Ecology, Dong-A University, 840 Hadan2-dong, Saha-gu, Busan 604-714, Korea

${ }^{3}$ Collaborative Innovation Center for Nanotech FIBER (nanoFIC), Shinshu University, Ueda, Nagano 386-8567, Japan

${ }^{4}$ Faculty of Engineering and Design, Kyoto Institute of Technology,Goshokaidou-cho, Matsugasaki, Sakyo-ku, Kyoto 606-8585, Japan 


\begin{abstract}
:
Structural development of isotactic polypropylene (iPP) fibers was analyzed in real time through in-situ WAXD/SAXS and fiber temperature measurements during $\mathrm{CO}_{2}$ laser-heated drawing because the $\mathrm{CO}_{2}$ laser irradiation can nearly fix the necking position on the running fiber. The in-situ WAXD/SAXS measurements were carried out with a high time-resolution of $0.4 \mathrm{~ms}$. The as-spun iPP fibers of two different initial structures were laser-heat-drawn to a draw ratio of 6.5. For the drawing of PP fiber containing mesophase structure, diffraction from the oriented mesophase remained until an elapsed time of $1.0 \mathrm{~ms}$, when oriented $\alpha$-phase crystal started to form. Meanwhile, for the drawing of PP fiber containing both an $\alpha$-phase and a mesophase structure, fragmented microcrystals were reorganized by orientation-induced crystallization before an elapsed time of $1.0 \mathrm{~ms}$. The long period increased drastically with fragmentation, and decreased with reorganization. The long period was about $16 \mathrm{~nm}$ for both drawn fibers.
\end{abstract}




\section{INTRODUCTION}

Polypropylene (PP) is the most widely used polymer, owing to its low density (ca. 0.9 $\left.\mathrm{g} / \mathrm{cm}^{3}\right)$, excellent processability, and high melting temperature $\left(T_{\mathrm{m}}\right.$, ca. $\left.160-170^{\circ} \mathrm{C}\right) . \mathrm{PP}$ possesses three tacticities associated with positioning of $\mathrm{CH}_{3}$ groups, among which isotactic PP (iPP) arranges same-sided $\mathrm{CH}_{3}$ groups along its backbone. iPP has several crystalline morphologies, depending on temperature and stress. Moreover, iPP can be crystallized predominately in the $\alpha$-monoclinic form by isothermal crystallization [1], slow cooling [2], or melt spinning [3]; this phase is the most stable and has unit-cell parameters $\mathrm{a}=0.665 \mathrm{~nm}, \mathrm{~b}=2.096 \mathrm{~nm}, \mathrm{c}=0.65 \mathrm{~nm}$, and $\beta=99.2^{\circ}$. The $\beta$-hexagonal and $\gamma$-triclinic phases may be crystallized from the melt under high undercooling or high pressure conditions, or by the addition of nucleating agents [4-8]. The mesophase has been identified in iPP quenched from the melt to below $0^{\circ} \mathrm{C}$ at a rate faster than $80^{\circ} \mathrm{C} / \mathrm{s}$ [9, 10], crystallized isothermally between 0 and $40^{\circ} \mathrm{C}$ [11], and spun at moderate take-up speeds, high extrusion temperatures, narrow molecular weight distributions, and low draw-down ratios [12-14]. The mesophase is not an imperfect crystal, but an ordered structure between that of the amorphous and crystalline phases [15]. The mesophase has been described as a smectic [16], paracrystalline [17-19], or partially ordered phase [20], which possesses a high degree of order in the direction of the chain axis but a low degree of order in its lateral packing. The morphology of the iPP mesophase on a nanoscopic scale is characterized by the so-called "nodule" of polygonal or spherical shapes, as observed by transmission electron microscopy (TEM) [21-23].

Several studies have been conducted on in-situ analysis of structural development in the drawing process for iPP fibers and films. Sakurai et al. [24] have studied the structural deformation behavior of iPP with different molecular characteristics; i.e., molecular weight distribution (MWD) and isotacticity (IT), during the hot drawing process, by in-situ time-resolved measurements of synchrotron-sourced WAXD and SAXS. The deformation behavior of the lamellar stacking structure was found to be significantly dependent on the molecular characteristics. Narrower MWD and higher IT developed only the lamellar stacking structure with c-axis crystallites oriented along the drawing direction detected at the deformation stage after necking, but for broader MWD and IT the oriented fibrillar structure was observed in addition to the lamellar stacking 
structure. Ran et al. [25, 26] have reported that on-line studies on structural and morphological changes during the heating and drawing process of iPP fibers were carried out using synchrotron SAXS and WAXD techniques. The $\alpha$-phase crystals were quite defective in the initial iPP fibers and were converted into the mesomorphic modification by drawing at room temperature. No obvious long period was observed in the mesophase of the iPP fiber. They postulated that the constituents of the mesophase in iPP fibers include oriented bundles of helical chains with random helical hands and perhaps oriented chains with no helical structures; both have only partial packing ordering. The $\alpha$-phase crystals were not converted into the mesophase by drawing at high temperature. At higher temperature, the $\alpha$-phase crystals became perfect and crystallinity increased when the fiber was drawn. Zuo et al. [27] have carried out in-situ SAXS/WAXD measurements to investigate the deformation-induced crystallization changes of iPP films during uniaxial stretching at different temperatures. At room temperature the structure was transformed from a folded chain crystal lamellar structure (monoclinic $\alpha$-phase) into an oriented mesophase, whereas at high temperature the structural change involves a transformation of the amorphous phase to an oriented folded chain crystal lamellar structure. Nozue et al. [28] have investigated the process of rearranging lamellar crystal structures in iPP during hot drawing by in-situ microbeam SAXS/WAXD and polarized optical microscopy measurements. The long period of perpendicular parent lamellae increased, and then disordering of the crystal packing structures along the a-axis started. When necking began, the long periods of parent and daughter lamellae started to decrease drastically with the alignment of the c-axis in the stretching direction. The ease of crystal fragmentation and c-axis alignment strongly depend on the type of lamellae, indicating the order of stress concentration during drawing.

Fiber structure is generally developed by orientation-induced crystallization via necking, and is complete within a few milliseconds after necking occurs. Fiber structure development around the necking point is difficult to monitor in practice because the necking point fluctuates widely within a range from several tens to several hundred times fiber diameter. The in-situ studies introduced previously [24-28] for iPP films and fibers were actually conducted with low time-resolution, involving very low deformation speed. This may because of the time required to heat the fiber or film 
homogeneously with conventional heating methods.

In our previous studies [29-33], we have reported a $\mathrm{CO}_{2}$ laser-heated continuous drawing technique, in which the necking position can be nearly fixed within $0.2 \mathrm{~mm}$, since laser irradiation can heat the running fiber rapidly and homogenously with no contact. $\mathrm{CO}_{2}$ laser-heat-drawing allowed in-situ measurement of the initial structure development with high time-resolution in the vicinity of the neck-drawing point.

Thus, in the present study, the initial fiber structure development of iPP fiber during a continuous drawing process was analyzed. For this purpose, the WAXD/SAXS patterns and the fiber temperature profiles were measured as a function of elapsed time after necking.

\section{EXPERIMENTAL}

\section{Fundamentals of in-situ Measurement}

The in-situ measurement system used in the present study is shown schematically in Figure 1. Details of the in-situ measurements can be found in previous papers [29-33]. As described in detail elsewhere, the running fiber was heated by means of a $\mathrm{CO}_{2}$ laser beam which was generated using a PIN-30R laser source manufactured by Onizuka Co. Ltd. The laser source had a rated power of $30 \pm 1.5 \mathrm{~W}$ with a beam diameter of $5 \mathrm{~mm}$. The running fiber was drawn by means of a speed differential between the feed and take-up rollers. The position where necking occurred was almost constant owing to rapid heating by the laser irradiation, and the neck-drawing process had high stability in a well-established steady state. WAXD/SAXS and fiber temperature were measured as a function of elapsed time $t$, which was calculated on the basis of the distance $D$ between the measurement and necking points, divided by the fiber running speed $v$. The distance $D$ was controlled by shifting the necking position by means of a traveling mirror unit.

\section{Materials and Drawing}

The present study used iPP pellets with melt flow rates (MFRs) of 20 and 30, which are referred to as iPP-I and iPP-II, respectively. They were purchased from Japan Polypropylene Co. The iPP fibers were produced by means of a melt-spinning apparatus; the spinning conditions are shown in Table 1. The obtained as-spun fibers had diameters within the range of $203 \pm 2$ to $209 \pm 2 \mu \mathrm{m}$. To obtain a nearly unoriented 
iPP fiber, the fiber was spun under almost no spinning tension. The as-spun iPP fibers were drawn to a draw ratio of 6.5 ; the drawing conditions are shown in Table 2 . The drawing was conducted with a high take-up speed of $130 \mathrm{~m} / \mathrm{min}$ because the laser irradiation heated the running fiber rapidly and homogeneously. The applied laser power was measured with a powermeter (SYNRAD Co, Ltd., PW-250). Drawing stress was measured in situ during the drawing process by means of a tensionmeter (EIKO SOKKI Co. Ltd., HS-1500S).

\section{Time Resolution}

Time resolution during continuous drawing was calculated to determine the confidence interval at every measurement point. The confidence interval was estimated by analyzing the necking behavior observed by a CCD camera in the continuous laser-drawing process. The time resolution was obtained by dividing the factor that controls the position resolution of the necking by the fiber running speed. The position resolution $\left(W_{x-\text { ray }}\right)$ is calculated using Eq. 1, based on the width of the X-ray beam $\left(W_{\text {beam }}\right)$, the fluctuation of the necking point $\left(W_{\text {neck }}\right)$, and the length of the necking deformation $\left(W_{\text {deform }}\right)$.

$$
W_{X-\text { ray }}=\sqrt{W_{\text {beam }}^{2}+W_{\text {neck }}^{2}+W_{\text {deform }}^{2}}
$$

From analysis of the deformation behavior observed by the CCD camera, $W_{\text {beam }}$ was found to be $201 \mu \mathrm{m}, W_{\text {neck }}$ was found to be 420 and $880 \mu \mathrm{m}$ for iPP-I and iPP-II, respectively, and $W_{\text {deform }}$ was found to be 142 and $160 \mu \mathrm{m}$, respectively. Accordingly, the time resolutions in the WAXD measurement were 0.3 and $0.4 \mathrm{~ms}$ for iPP-I and iPP-II, and in the SAXS measurement the time resolutions were 0.4 and $0.5 \mathrm{~ms}$, respectively.

\section{X-ray Diffraction Measurements}

Beam line 40B2 of the synchrotron radiation X-ray source in SPring- 8 was used in this study. WAXD and SAXS images were taken by a $3000 \times 3000$ pixel imaging plate with vacuum chambers of 250 and $2000 \mathrm{~mm}$ length, respectively. The wavelength and the 
exposure time for WAXD and SAXS measurements were 0.1 and $0.15 \mathrm{~nm}$, and 180 and 1200 s, respectively. The obtained WAXD and SAXS images were calibrated using diffraction patterns of lead dioxide $\left(\mathrm{PbO}_{2}\right)$ and lead stearate $(\mathrm{StPb})$. The necking position was determined from the transmitted X-ray intensity profile obtained through the ion chamber [29]. The polyimide diffraction peak was included in the WAXD images by means of a polyimide film mounted on the vacuum chamber, and the diffraction image was later used as a reference profile when compensating for background scattering by subtracting the blank image. Details on the in-situ WAXD and SAXS measurements can be found in previous reports $[29,30]$.

\section{Fiber Temperature Measurement}

The fiber temperature was measured by means of a $\mathrm{C}-\mathrm{H}$ infrared thermo-spot sensor (TNZ7-J0-2.5K0.2 type, Japan Sensor Co., Ltd), equipped with a MCT detector and an interference filter. The spot diameter was $200 \mu \mathrm{m}$ and the response time was $100 \mathrm{~ms}$. The interference filter transmits a wavelength of 3 to $4 \mu \mathrm{m}$, which corresponds to the absorbance band (2800-3000 $\mathrm{cm}^{-1}$ ) attributable to $\mathrm{C}-\mathrm{H}$ stretching. Fiber temperature was calculated from the radiation intensity averaged for $30 \mathrm{~s}$ at each measurement point. The in-situ fiber temperature measurement was conducted in the same manner as in the previous studies [29-33].

\section{RESULTS AND DISCUSSION}

\section{Fiber Temperature}

Figure 2 shows fiber temperature change as a function of distance from the necking point during the laser drawing of iPP-II. The gray-shaded area denotes the region of laser irradiation, and the horizontal axis denotes the position where the necking occurred. Fiber temperature was measured twice so as to reduce experimental error, and two results are shown together in the figure. Fiber temperature increased to about $80^{\circ} \mathrm{C}$ by laser irradiation before necking, and jumped to approximately $150^{\circ} \mathrm{C}$ during necking. As has been discussed, this jump in temperature just after necking occurs was caused by an exothermic effect associated with plastic deformation [22, 29]. 


\section{WAXD Analyses}

Figure 3 shows WAXD images taken at various elapsed times for iPP-I and iPP-II; the elapsed times are noted under the individual WAXD images and by the respective WAXD intensity profiles. WAXD intensity profiles along the equatorial direction for iPP-I and iPP-II are shown in Figure 4. The negative elapsed time, $-2.5 \mathrm{~ms}$, represents the time before necking; that is, the undrawn fiber. Before necking occurred, iPP-I showed two broad Debye-Scherrer rings, indicating an unoriented mesophase, whereas iPP-II exhibited rings due to unoriented crystals in addition to the mesophase. The intensity profile for iPP-II also showed $\alpha$-phase diffractions of (110), (040), and (130) along the equatorial direction before necking. The initial Debye-Scherrer rings for iPP-I and iPP-II are concentrated on the equator and off-meridian just after necking, indicating that the molecular chains were oriented along the drawing direction. In iPP-I, a broad diffraction due to oriented mesophase developed immediately after necking occurred and hardly changed for an elapsed time of $1.0 \mathrm{~ms}$. After $1.5 \mathrm{~ms}$, the broad peak became asymmetric, indicating the onset of oriented $\alpha$-phase formation. In iPP-II, the intensity of $\alpha$-phase diffraction decreased drastically immediately after necking. For elapsed times of -0.3 to $0.4 \mathrm{~ms}$, an asymmetric broad diffraction peak was observed instead of the $\alpha$-phase diffractions. As time elapsed, the broad diffraction became more asymmetric, and after $0.75 \mathrm{~ms}$, the intensity of $\alpha$-phase diffractions increased. This phenomenon in iPP-II partially corresponds to those reported by some researchers [26, 27], who found that drawing at room temperature transformed the $\alpha$-phase into the mesophase. The formation of the mesophase occurs through destruction of the lamellar crystalline phase; i.e., lamellar fragmentation, by pulling chains out from crystals. Several researchers suggested that the mesophase contains oriented bundles of helical chains with random helical hands $[2,26]$ and is composed of microcrystals of the $\alpha$-phase [34]. Accordingly, in iPP-I, we assumed that the helical chains of the initial mesophase most likely became oriented with elapsed time after necking, and after 1.0 ms, small-sized microcrystals were organized and formed the oriented $\alpha$-phase. In contrast, in iPP-II, we believe that the lamellar crystal of the $\alpha$-phase observed initially was fragmented with necking into small-sized microcrystals, and the $\alpha$-phase was reorganized by orientation-induced crystallization with increasing elapsed time. 


\section{Orientation-induced Crystallization}

The WAXD intensity profiles of iPP-II were peak-fitted to a Gaussian function (Eq. 2). The position $\theta_{0}$ and full width at half maximum $\sigma$ of the diffractions were determined using Eq. 2. The beam deviation effect on $\sigma$ was corrected by the width of the intensity profiles of $\mathrm{StPb}$ and $\mathrm{PbO}_{2}$. $\mathrm{D}$-spacing $d$ and crystallite size $D$ were calculated by Bragg's equation (Eq. 3) and Scherer's equation (Eq. 4), respectively, where the constant $k$ is 0.918 . The crystal orientation factor was estimated from the azimuthal intensity profiles for the (110), (040), and (130) planes, and the azimuthal intensity profiles were fitted by a Pearson VII equation (Eq. 5). The crystal orientation $f$ was calculated using Eq. 6.

$$
\begin{gathered}
I(\phi)=I_{0} \exp \left\{-4 \ln 2 \cdot\left(\frac{\theta-\theta_{0}}{\sigma}\right)^{2}\right\} \\
2 d \sin \theta_{0}=\lambda \\
D=\frac{k \lambda}{\sigma \sin \theta_{0}} \\
I(\beta)=-\frac{I_{0}}{\left\{1+4\left(\frac{\beta-\beta_{0}}{\tau}\right)^{2}\left(2^{\frac{1}{2.5}}-1\right)\right\}^{2.5}} \\
\left.f=\frac{3\left\langle\cos ^{2} \beta\right\rangle-1}{2} \quad, \quad \cos ^{2} \beta\right\rangle=\frac{\int_{0}^{\pi / 2} I(\beta) \cos ^{2} \beta \sin \beta d \beta}{\int_{0}^{\pi / 2} I(\beta) \sin \beta d \beta}
\end{gathered}
$$

Crystal parameters were calculated using the above equations. Figure 5 shows the crystallinity index of the $\alpha$-phase with elapsed time, which was estimated by the integral intensity of the fitted equatorial diffractions. The index increased mainly before $4 \mathrm{~ms}$ after necking. It was almost saturated after $4 \mathrm{~ms}$, but continued to increase to the value for the drawn fiber.

The crystal orientation factors for the $\alpha$-phase (110), (040), and (130) diffractions and the mesophase diffraction are plotted against elapsed time in Figure 6. Between 0.1 and $0.4 \mathrm{~ms}$, the orientation factor for the mesophase was obtained using two Gaussian 
distributions for amorphous and mesophase diffractions, assuming that the lower diffraction peak is a (hk0) plane of the mesophase. The mesophase orientation increased with elapsed time. After recrystallization of the $\alpha$-phase, the orientation factor for the crystal increased gradually, and at $4.0 \mathrm{~ms}$ almost saturated at about 0.98 . This increase in the orientation factor corresponds with that of the crystallinity index.

The d-spacings of the $\alpha$-phase (110), (130), and (040) diffractions for iPP-II fiber were plotted as a function of elapsed time, as shown in Figure 7. The d-spacing during the drawing process did not show a significant change with elapsed time after necking, but the d-spacing of (040) diffraction for drawn fiber shows a clear decrease. The decreasing of d-spacing in the drawn fiber seems to be caused by the density increase of unit cell by thermal shrinking after drawing. Isasi et al. [35] have reported that the b-axis dimension undergoes a large thermal expansion with temperature, whereas the change along the a-axis is relatively small, and, as a consequence of the $3_{1}$ helical conformation of the chain, the c-axis dimension is less sensitive to temperature. In this regard, Lotz et al. [36, 37] have suggested that the $\alpha$-phase forms by interdigitation of methyl groups of rows of right-handed helices onto left-handed ones in the c-a plane. The interdigitation restricts thermal expansion along the c- and a-axes. Crystallite sizes deduced from the $\alpha$-phase (110), (130), and (040) diffractions for iPP-II fiber are shown in Figure 8. Although the $\alpha$-phase crystal was fragmented and recrystallized during the neck-drawing process, the crystallite sizes remained almost constant.

\section{SAXS Analyses}

SAXS images taken at various elapsed times for iPP-I and iPP-II fibers and their intensity profiles are shown in Figures 9 and 10, respectively. SAXS intensity profiles were peak-fitted using a Gaussian function (Eq. 2), and the long periods for iPP-I and iPP-II were calculated using Eq. 7 and are shown in Figure 11.

$$
2 L \sin \theta_{0}=k \lambda
$$

In the undrawn fibers for both samples, at $-2.5 \mathrm{~ms}$, low-oriented broad scattering was observed in the meridian, indicating unoriented lamellar structure with respect to the fiber axis. Before necking, both samples were almost uniform in supermolecular structure. This structure seemed to be formed under natural attenuation without external 
stress in the melt spinning. iPP-I revealed two streaks in the meridian just after necking and did not change with elapsed time. The long period of about $12 \mathrm{~nm}$ before necking increased to around $16 \mathrm{~nm}$ following necking. The increase may be attributable to the orientation of the helical chains with random helical hands. On the other hand, in iPP-II, immediately after necking, a weak two-pointed pattern was observed in the smaller angle side of the meridian, and equatorial streaks appeared simultaneously. The long period increased drastically just after necking. This may indicate that lamellar fragmentation by pulling chains out from the crystal partially destroyed the initial lamellar stacks. Simultaneously, a defective structure containing microvoids may have been formed. The scattering intensities decreased considerably. When the $\alpha$-phase crystal began to form, the long period decreased considerably at $1 \mathrm{~ms}$ and then nearly leveled off, showing a slight decrease from that of the drawn fiber. Ultimately, the long period became almost the same as that for iPP-I, at approximately $16 \mathrm{~nm}$.

\section{CONCLUSION}

Structural development of iPP fibers was analyzed by in-situ X-ray scattering measurements with a high time-resolution of about $0.4 \mathrm{~ms}$ during $\mathrm{CO}_{2}$ laser drawing. In the laser-drawing process, necking occurred when the fiber temperature increased to about $80^{\circ} \mathrm{C}$. Two kinds of as-spun fibers were drawn, referred to as iPP-I and iPP-II. iPP-I initially contained an unoriented mesophase, whereas iPP-II possessed a mixture of unoriented mesophase and $\alpha$-phase. Just after necking, in iPP-I, an oriented mesophase developed and remained almost unchanged for an elapsed time of $1.0 \mathrm{~ms}$, when the oriented $\alpha$-phase crystal_began to form. The long period of about $12 \mathrm{~nm}$ before necking increased to around $16 \mathrm{~nm}$ after necking. On the other hand, in iPP-II, the initial $\alpha$-phase lamellar crystal was fragmented during necking into small-sized microcrystals, and the $\alpha$-phase crystal was reorganized by orientation-induced crystallization as time progressed. This lamellar fragmentation by pulling chains out from the crystal probably partially destroyed the initial lamellar stacks. Simultaneously, a defective structure containing microvoids may have been formed. The long period became almost the same as that for iPP-I, at approximately $16 \mathrm{~nm}$. Higher time-resolution was needed for analyzing minutely the reorganization process of PP in the continuous fiber drawing. 


\section{Acknowledgements:}

The synchrotron radiation experiments were performed at BLA0B2 in SPring-8 with the approval of the Japan Synchrotron Radiation Research Institute (JASRI) (Proposal Nos. 2007B1226 and 2008A1485). This research was supported by Grant-in-Aid No. 18550191 and by a Research Grant for JSPS Postdoctoral Fellows No. P06091 from the Japan Society for the Promotion of Science. Also, this work was supported by an "Innovation Creative Center for Advanced Interdisciplinary Research Areas (Shinshu University)” project in special coordination funds for promoting science and technology of the Ministry of Education, Culture, Sports, Science and Technology, the Japanese government.

\section{REFERENCES}

[1] Kim YC, Ahn W, Kim CY. Polym Eng Sci 1997;37:1003-11.

[2] Natta GJ. Polym Sci 1955;16:143-54.

[3] Lengyel M, Mathe K, Bodor G. Acta Chim Acad Sci Hung 1977;94:309-20.

[4] Broda JJ, Appl Polym Sci 2003;89:3364-70.

[5] Kardos JL, Christia AW, Baer E. J Polym Sci Part A-2 Polym Phys 1966;4(5):777-88.

[6] Libster D, Aserin A, Garti N. Polym Adv Tech 2007;18:685-95.

[7] Romankiewicz A, Sterzynski T, Brostow W. Polym Int 2004;53:2086-91.

[8] Varga J, Ehrenstein GW. Polymer 1996;37(26):5959-63.

[9] Gailey JA, Ralston RH. SPE Trans 1964;4:29-33.

[10] Hanna LA, Hendra PJ, Maddams W, Willis HA, Zichy V, Cudby MEA. Polymer 1988;29:1843-7.

[11] De Santis F, Adamovsky S, Titomanlio G, Schick C. Macromolecules 2007;40:9026-31.

[12] Zhang XQ, Li RB, Kong L, Wang DJ. Polymer 2008;49:1350-55.

[13] Choi DM, White JL. Polym Eng Sci. 2004;44:210-22.

[14] Andreassen E, Grostad K, Myhre OJ, Braathen MD, Hinrichsen EL, Syre AMV, Lovgren TB. J Appl Polym Sci 1995;57:1075-84.

[15] Konishi T, Nishida K, Kanaya T, Kaji K. Macromolecules 2005;38:8749-54. 
[16] Natta G, Peraldo M, Corradini P. Rend Accad Naz Lincei 1959;26:14-7.

[17] Miller RL. Polymer 1960;1:135-43.

[18] Zannetti R, Celotti G, Armigliato A. Eur Polym J 1970;6:879-89.

[19] Hosemann R. J Appl Phys 1963;34(1):25-41.

[20] Gailey JA, Ralston PH. Polym Eng Sci 1968;8:202-09.

[21] Hsu CC, Geil PH, Miyaji H, Asai K. J Polym Sci Part B Polym Phys $1986 ; 24: 2379-401$.

[22] Ogawa T, Miyaji H, Asai K. J Phys Soc Jpn 1985;54:3668-70.

[23] Grubb DT, Yoon DY. Polym Commun 1986;27:84-8.

[24] Sakurai T, Nozue Y, Kasahara T, Mizunuma K, Yamaguchi N, Tashiro K, Amemiya Y. Polymer 2005;46(20):8846-58.

[25] Ran S, Zong X, Fang D, Hsiao BS, Chu B, Cunniff P, Phillips RA. J Mater Sci 2001;36:3071-77.

[26] Ran S, Zong X, Fang D, Hsiao BS, Chu B, Phillips RA. Macromolecules 2001;34:2569-78.

[27] Zuo F, Keum JK, Chen X, Hsiao BS, Chen H, Lai SY, Wevers R, Li J. polymer 2007;48:6867-80

[28] Nozue Y, Shinohara Y, Ogawa Y, Sakurai T, Hori H, Kasahara T, Yamaguchi

N, Yagi N, Amemiya Y. Macromolecules 2007;40:2036-45.

[29] Yamaguchi T, Komoriyama K, Ohkoshi Y, Urakawa H, Gotoh Y, Terasawa N, Nagura M, Kajiwara K. J Polym Sci Part B Polym Phys 2005;43:1090-99.

[30] Yamaguchi T, Kim KH, Murata T, Koide M, Hitoosa S, Urakawa H, Ohkoshi Y, Gotoh Y, Nagura M, Kodera M, Kajiwara K. J Polym Sci Part B Polym Phys 2008;46:2126-42.

[31] Kim KH, Kang YA, Murata T, Ikehata S, Ohkoshi Y, Gotoh Y, Nagura M, Koide M, Urakawa H, Kotera M. Polymer 2008;49:5705-13.

[32] Kim KH, Yamaguchi T, Ohkoshi Y, Gotoh Y, Nagura M, Urakawa H, Kodera M, Kikutani T. J Polym Sci Part B Polym Phys 2009;47(17):1653-65.

[33] Kim KH, Aida R, Kang YA, Ohkoshi Y, Gotoh Y, Nagura M, Urakawa H. Polymer 2009;50(19):4429-31.

[34] Farrow G. J Appl Polym Sci 1965;9:1227-32.

[35] Isasi JR, Alamo RG, Mandelkern L. J Polym Sci Part B Polym Phys 
1997;35:2945-49.

[36] Lotz B, Wittmann JC. J Polym Sci Part B Polym Phys 1986;24:1541-58.

[37] Lotz B, Wittmann JC, Lovinger AJ. Polymer 1996;37:4979-92. 


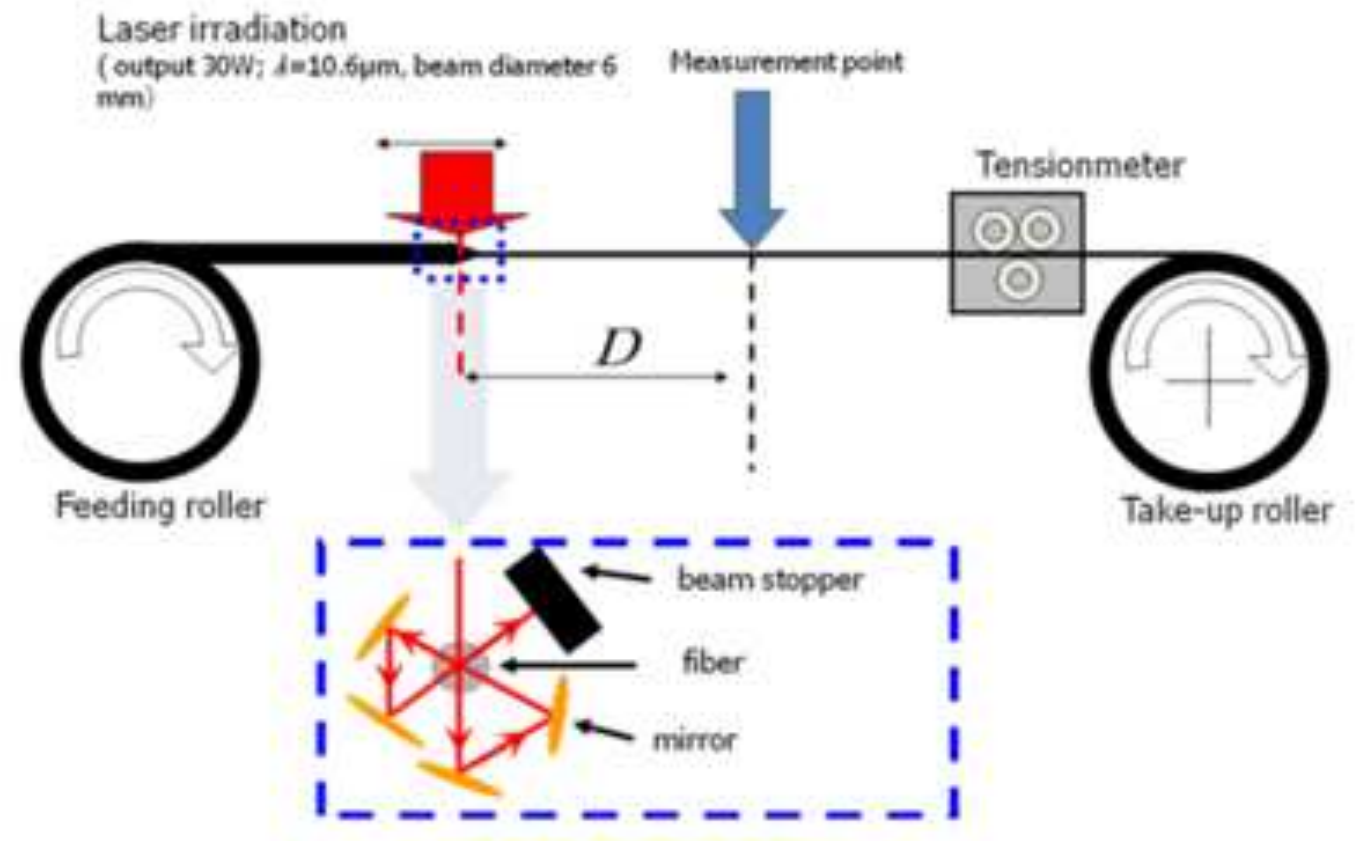

Figure $1 \mathrm{Schematics} \mathrm{of} \mathrm{on-line} \mathrm{measurement} \mathrm{system} \mathrm{for} \mathrm{CO}_{2}$ laser drawing. 


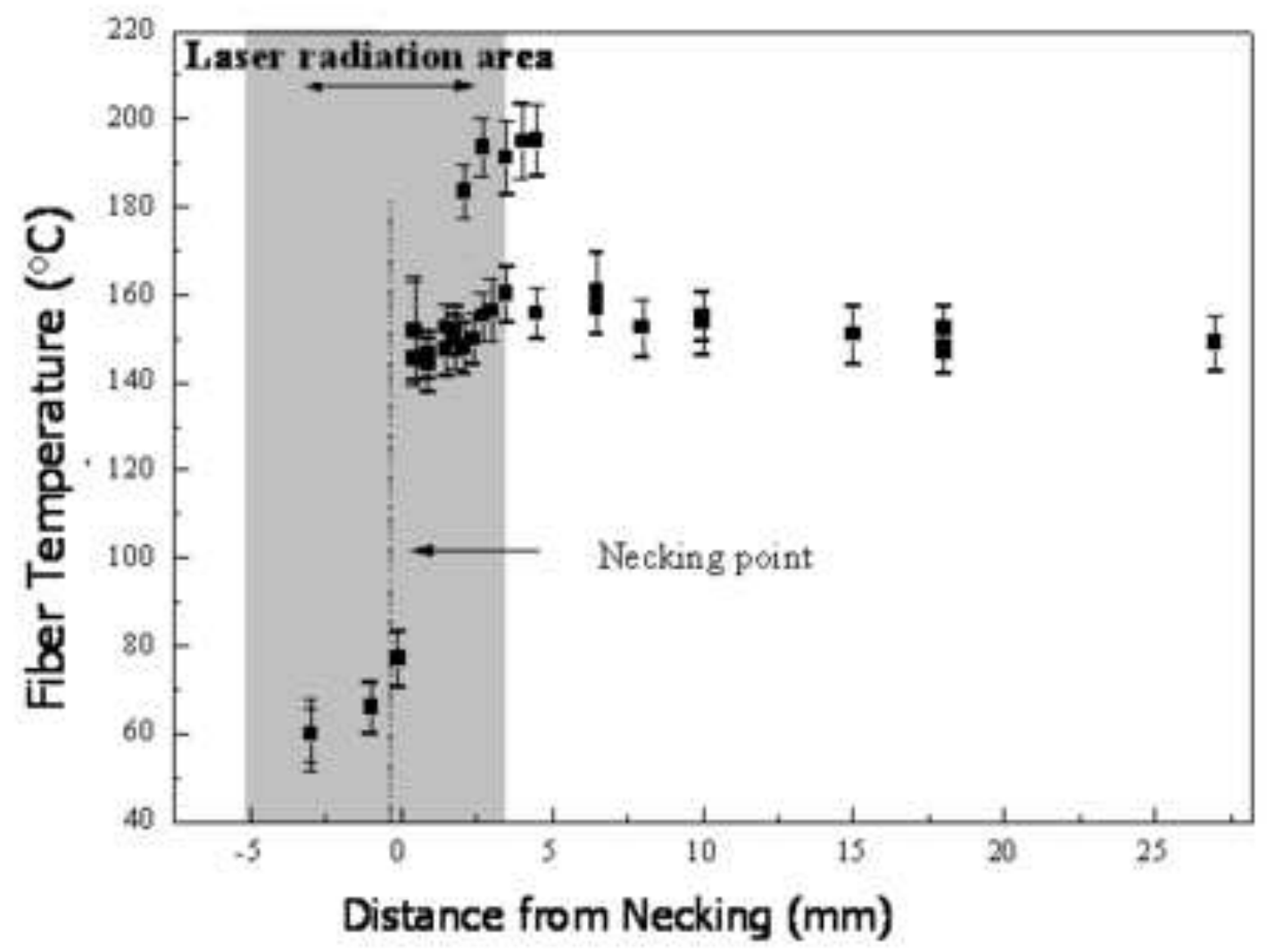

Figure 2 Fiber temperature change as a function of distance from the necking position for iPP-II. 


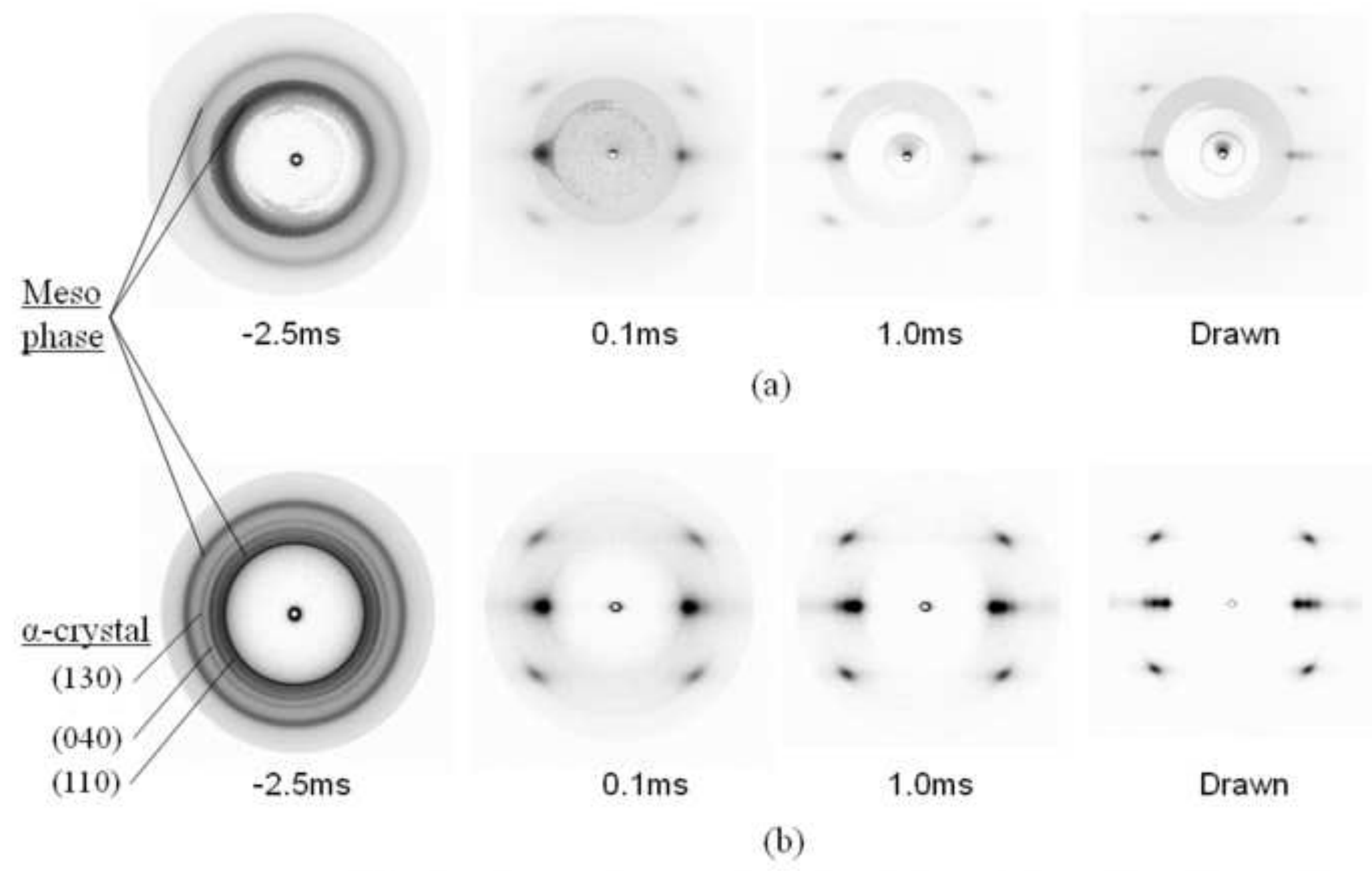

Figure 3WAXD diffraction images taken at various elapsed times for iPP-I (a) and iPP-II (b) 


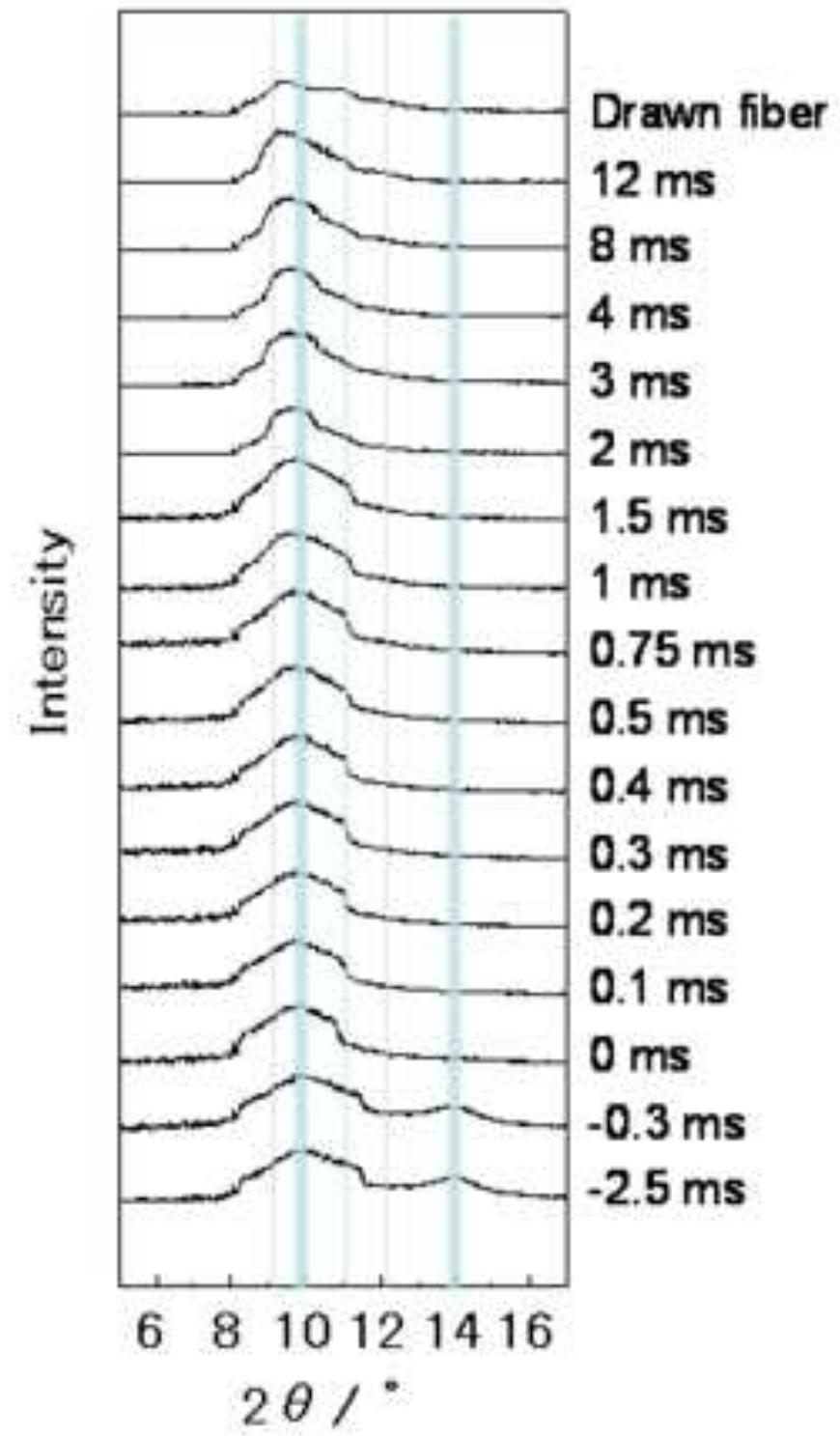

(a)

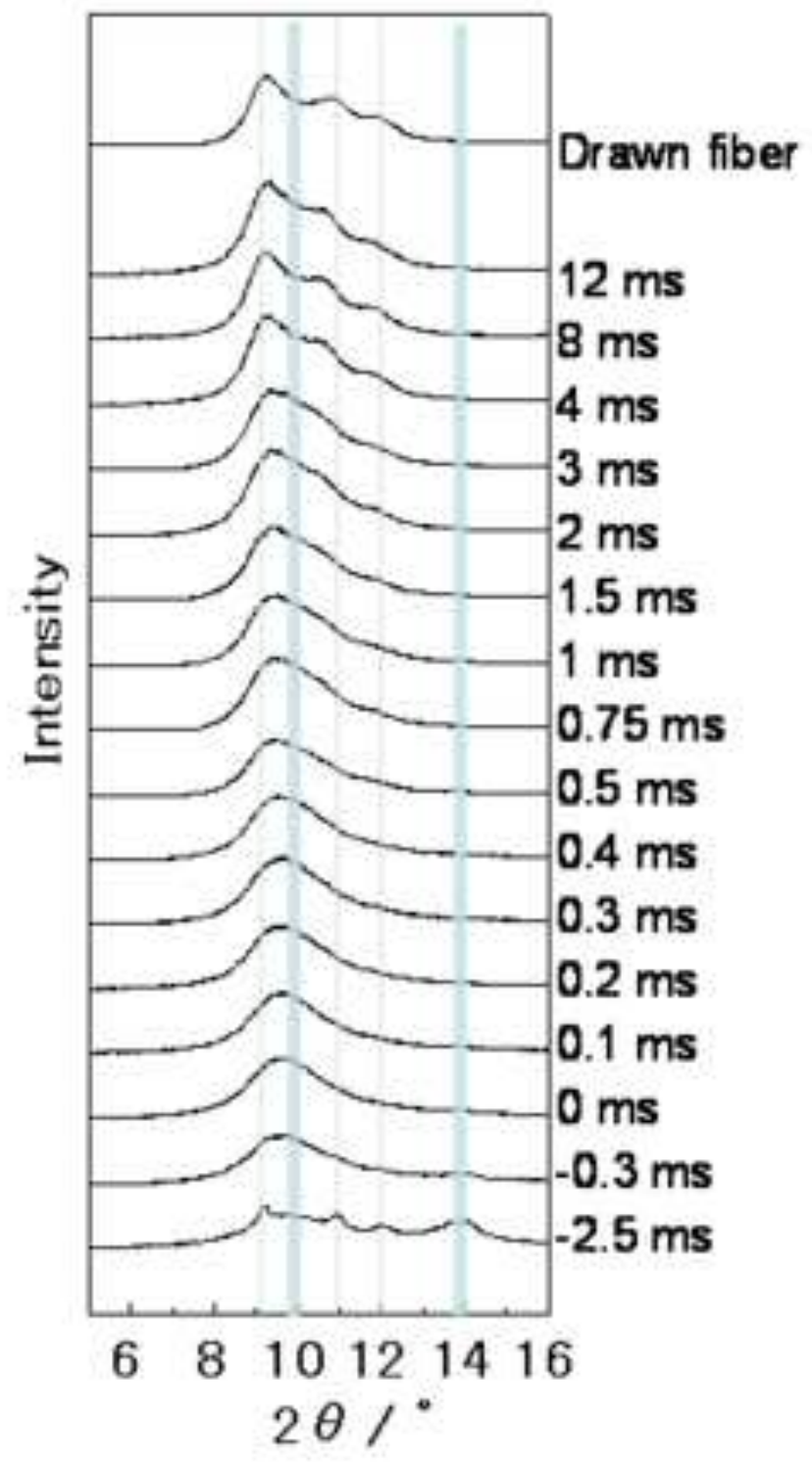

(b)

Figure 4 WAXD intensity profiles along equatorial direction: (a) iPP-I, (b) iPP-II 


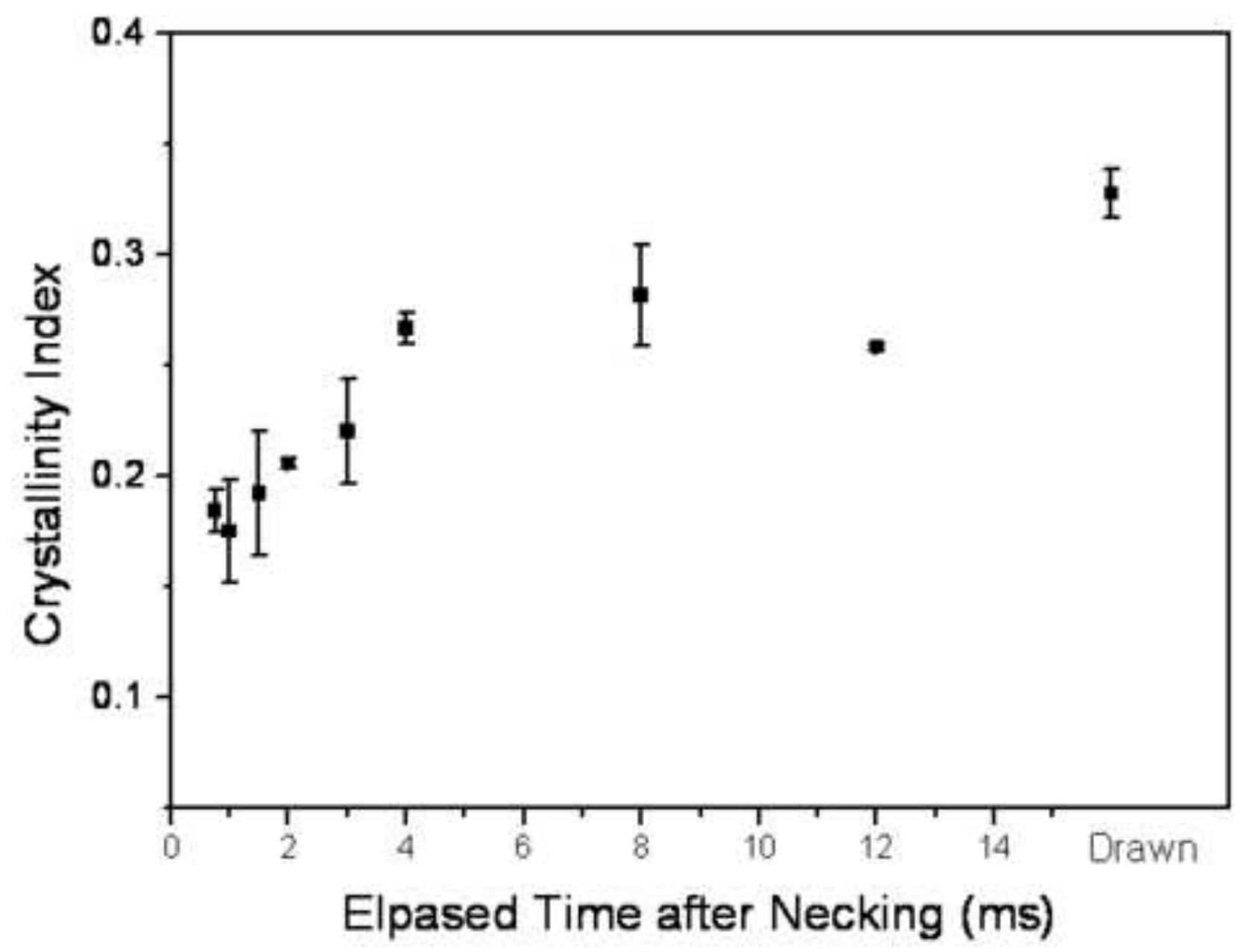

Figure 5 Crystallinity index with elapsed time for iPP-II 


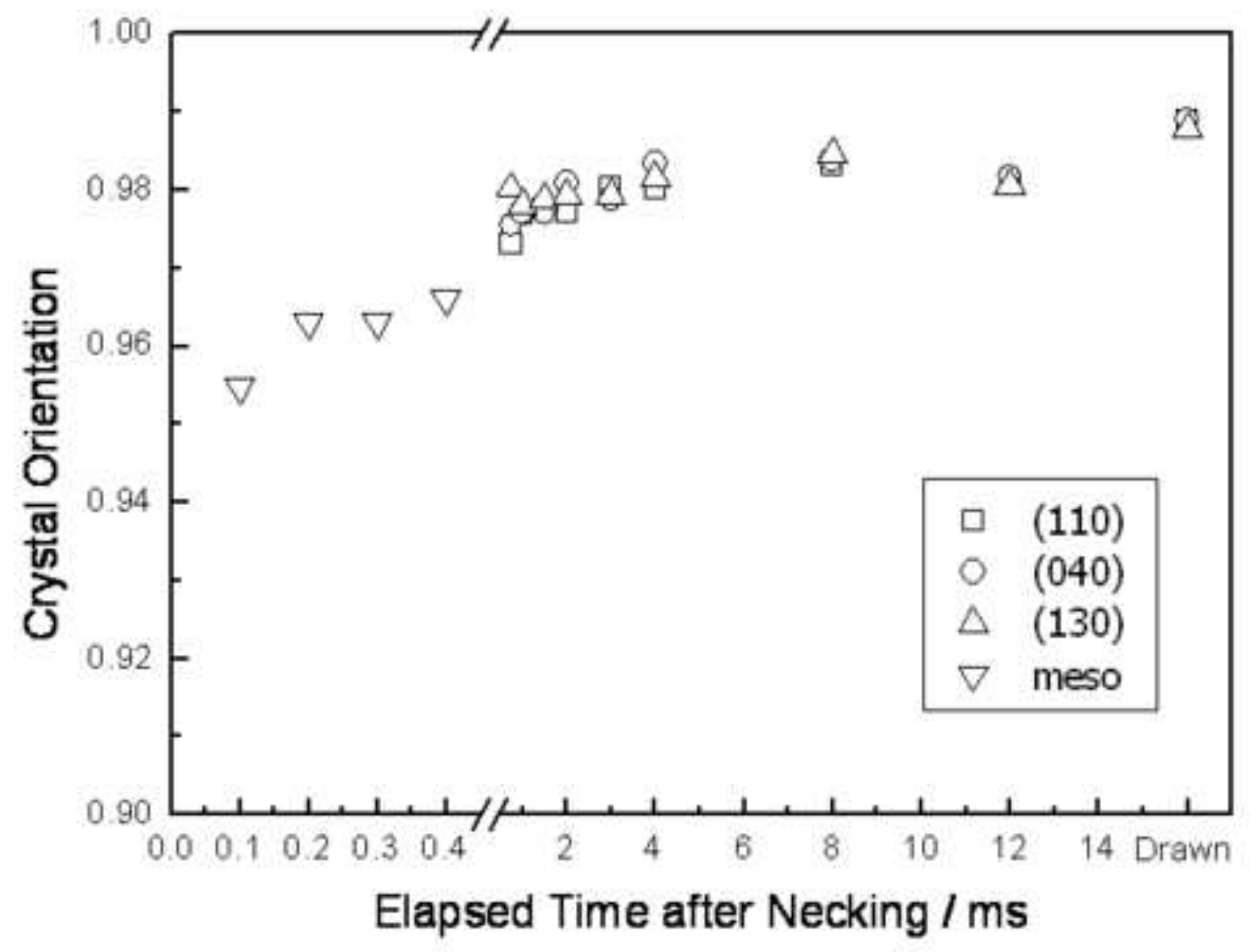

Figure 6 Crystal orientation factor with elapsed time for iPP-II 


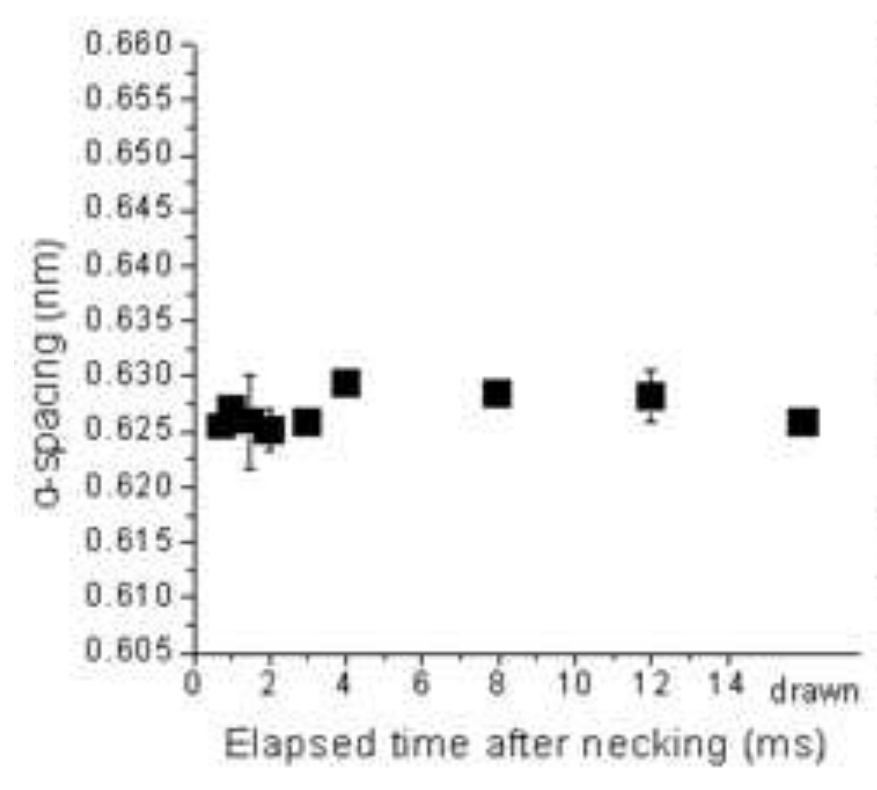

(a)

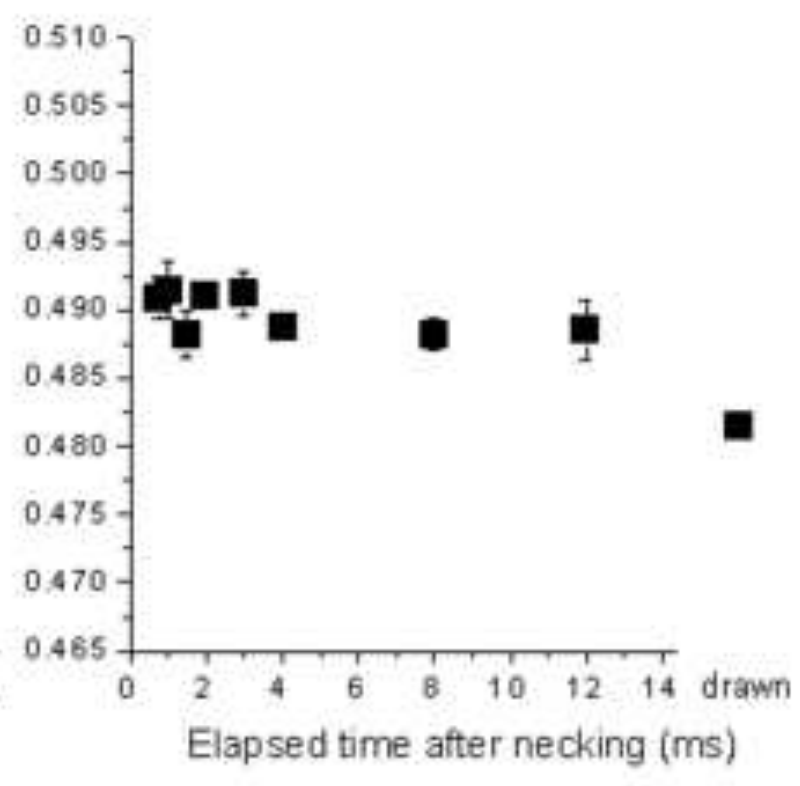

(b)

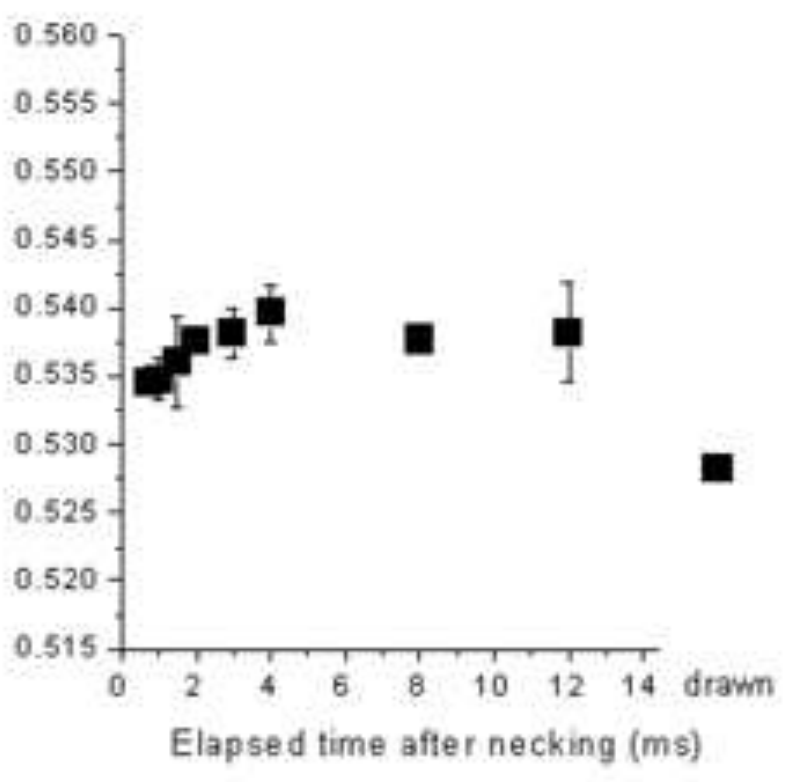

(c)

Figure 7 D-spacings for iPP-II fiber: (a) (110), (b) (130), (c) (040) planes. 


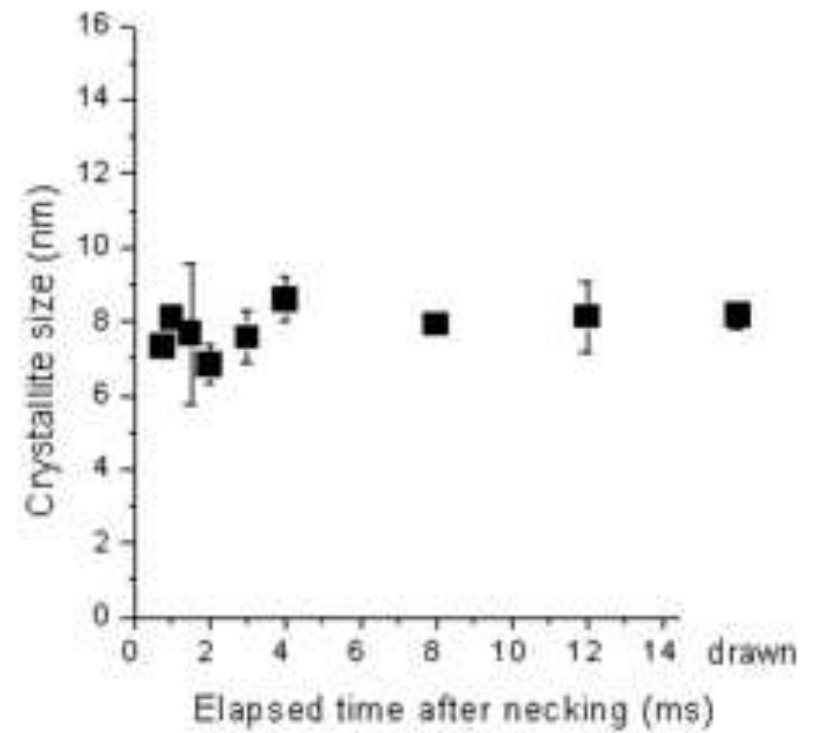

(a)

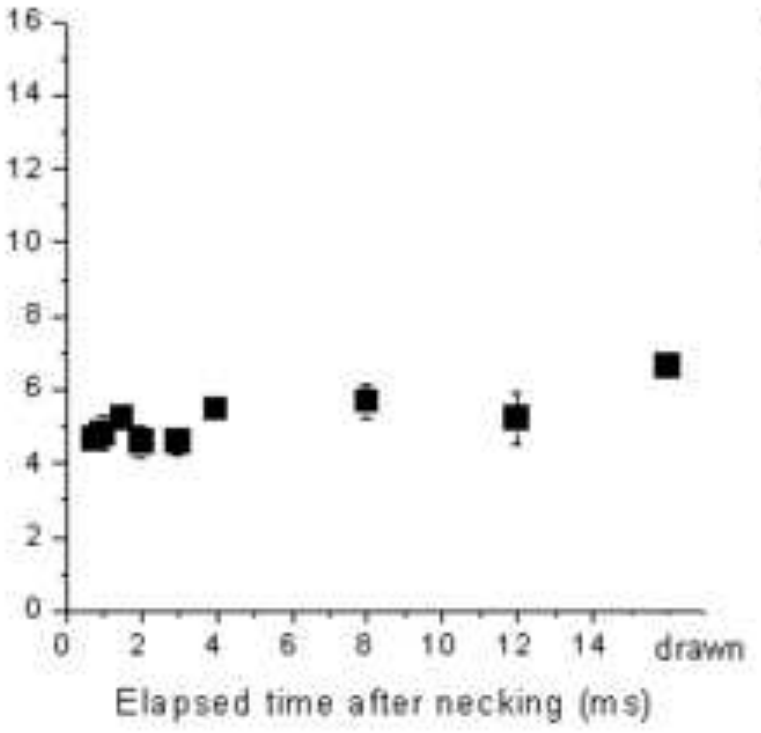

(b)

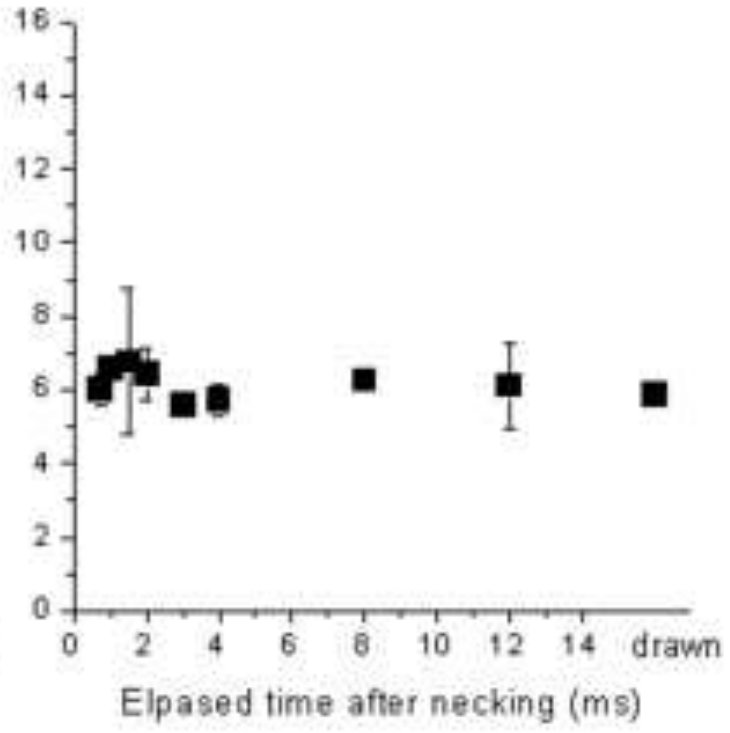

(c)

Figure 8 Crystallite sizes for iPP-II fiber: (a) (110), (b) (130), (c) (040) planes. 
Figure(s)

$-2.5 \mathrm{~ms}$

$0.15 \mathrm{~ms}$

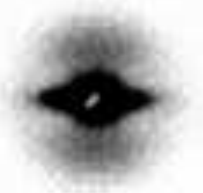

$-2.5 \mathrm{~ms}$

$0.15 \mathrm{~ms}$

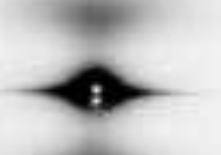

(a)

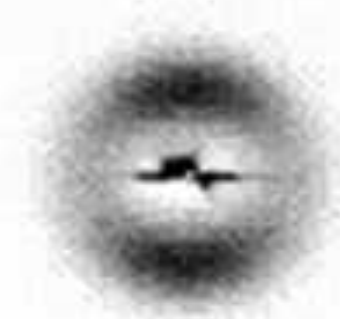

$1.0 \mathrm{~ms}$

drawn
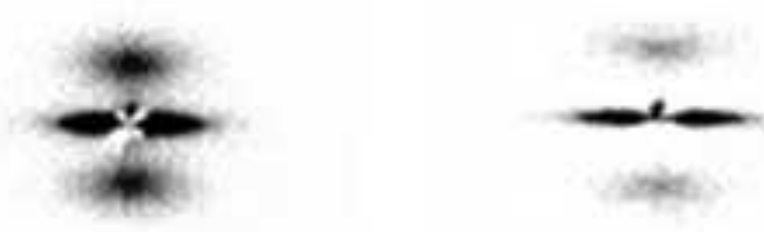

$1.0 \mathrm{~ms}$

(b)

Figure 9 SAXS images obtained at various elapsed times for iPP-I (a) and iPP-II (b). 


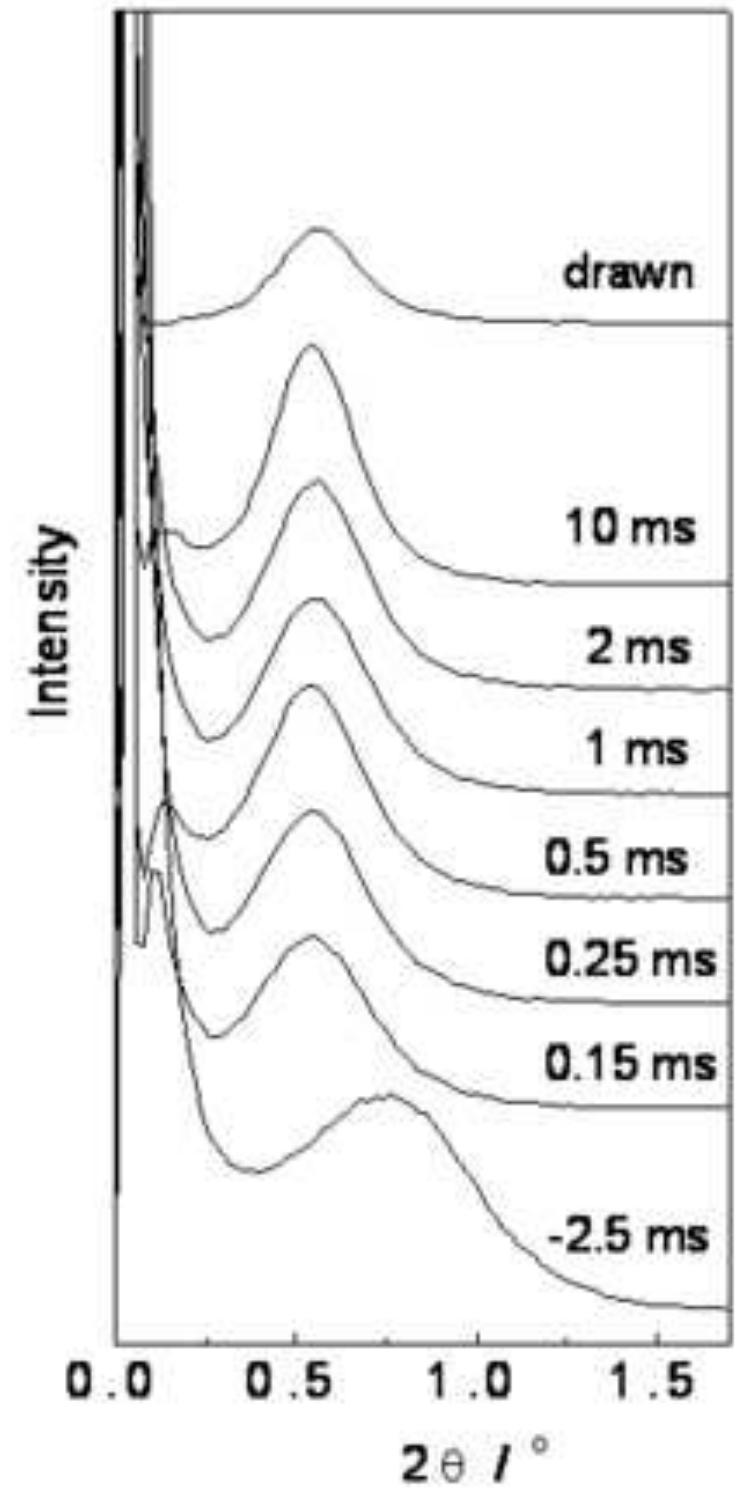

(a)

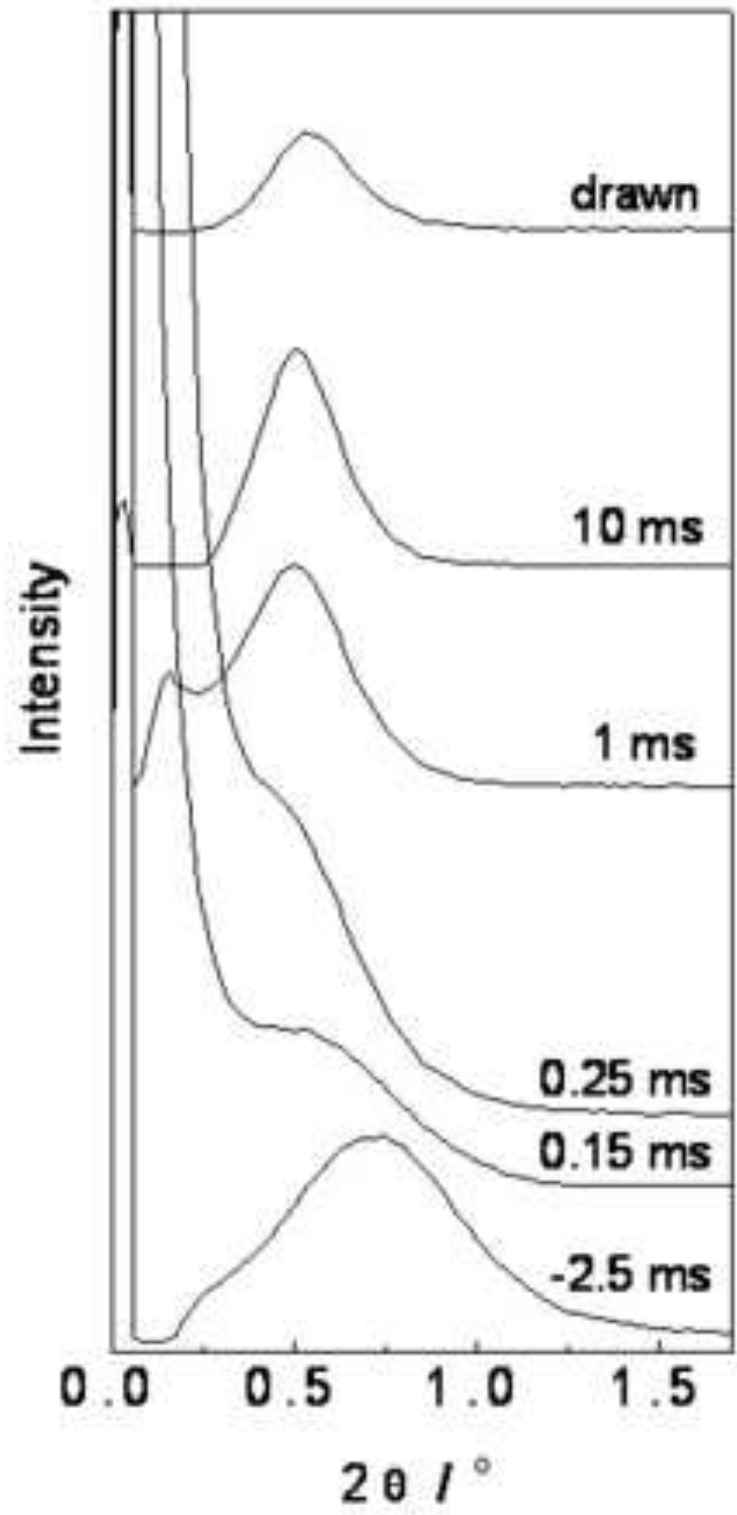

(b)

Figure 10 Meridian SAXS intensity profiles of iPP fiber: (a) iPP-I and (b) iPP-II. 


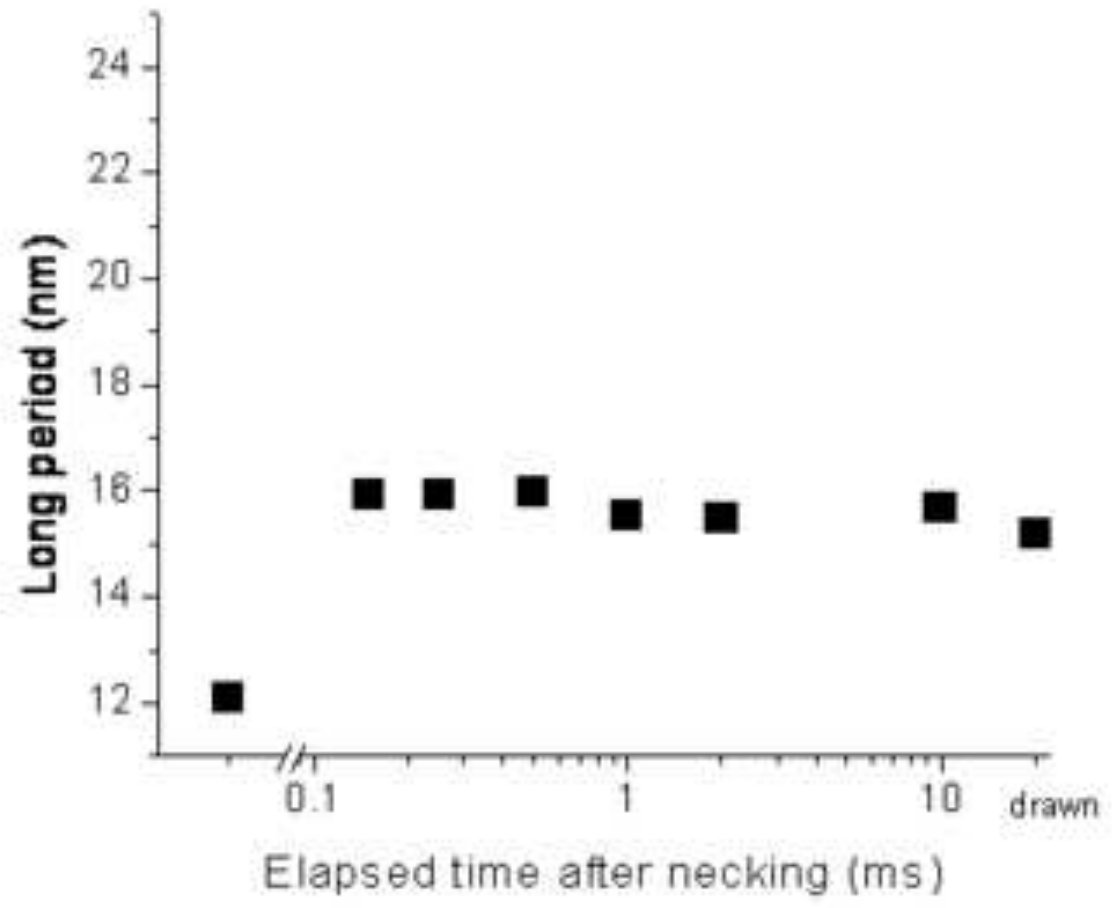

(a)

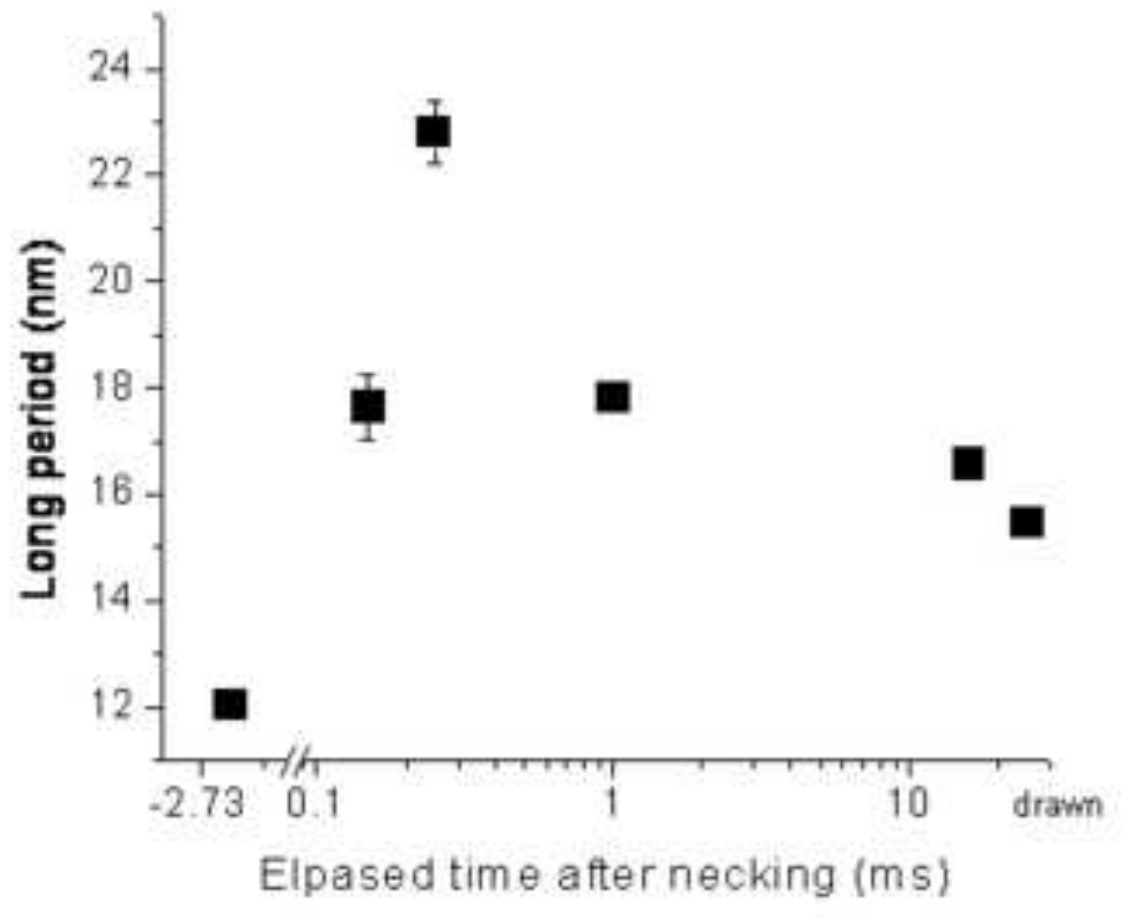

(b)

Figure 11 Long period with elapsed time: (a) iPP-I and (b) iPP-II 
Table 1 Spinning conditions

\begin{tabular}{|l|l|l|}
\hline Sample & iPP-I & iPP-II \\
\hline Spinning Temp. $\left({ }^{\circ} \mathrm{C}\right)$ & 250 & 230 \\
Mass Flow Rate $(\mathrm{g} / \mathrm{min})$ & 3.82 & 3.90 \\
Environment Temp $\left({ }^{\circ} \mathrm{C}\right)$ & 19 & 23 \\
Take-up Speed $(\mathrm{m} / \mathrm{min})$ & 135 & 136 \\
Diameter $(\mu \mathrm{m})$ & $209 \pm 2$ & $203 \pm 2$ \\
\hline
\end{tabular}


Table 2 Drawing conditions

\begin{tabular}{|l|l|l|}
\hline Sample & iPP-I & iPP-II \\
\hline Draw Ratio & 6.5 & 6.5 \\
Laser Power (W) & $27 \sim 31$ & $26 \sim 31$ \\
$\begin{array}{l}\text { Take-up Speed (m/min) } \\
\text { Drawing Stress (MPa) } \\
\text { in WAXD/SAXS measurements } \\
\begin{array}{l}\text { Drawing Stress (MPa) } \\
\text { in fiber temperature measurements }\end{array}\end{array}$ & 130 & 130 \\
\hline
\end{tabular}

